\title{
A Hexaplex PCR Assay Developed for Simultaneous Detection of Bacillus anthracis and Yersinia pestis and Distinguish Their Virulence Levels Tested on Vietnamese Samples
}

\author{
Son Thai Nguyen ${ }^{1}$ (D) Hang Thi Thu Dinh $^{2} \cdot$ Minh Ngoc Nghiem ${ }^{3}$
}

Accepted: 9 May 2019 / Published online: 24 May 2019

(C) The Author(s) 2019

\begin{abstract}
Bacillus anthracis and Yersinia pestis are at high risk of bioterrorism, but they have different strains of virulence that exist in the natural environment, making it difficult to diagnose the risk of disease. This study aimed to develop a novel hexaplex PCR assay to simultaneously detect $B$. anthracis and $Y$. pestis and quickly distinguish their virulence levels. The vrrA, pagA, and capA genes from B. anthracis and ypo2088, pla, and cafl genes from Y. pestis were specifically amplified to generate six PCR fragments of 222,751 , and 610 and 103, 438, and 271 bp, respectively. Furthermore, a recombinant competitive internal amplification control was designed in the assay, which coamplified with the capA gene primer pairs, producing a fragment of $1000 \mathrm{bp}$ in length. Thirtyeight bacterial strains including 4 reference strains and 34 screening strains derived from human, herbivores, and environments in the North of Vietnam, as well as spiked soil samples, were used to evaluate the assay. The new hexaplex PCR assay was in accordance with the conventional culture methods to detect $B$. anthracis and $Y$. pestis. In addition, this assay can be quickly discriminated among pathogenic and non-pathogenic B. anthracis and Y. pestis strains, as well as rapidly differentiate levels of virulence among strains isolated from human and soil samples in some areas of Vietnam. The new hexaplex PCR is a useful tool in screening for both pathogenic and non-pathogenic B. anthracis and $Y$. pestis, necessary in use for biodefense purposes and disease prevention.
\end{abstract}

Keywords Bacillus anthracis $\cdot$ Yersinia pestis $\cdot$ Hexaplex PCR $\cdot$ Internal amplification control $\cdot$ Pathogenic

Son Thai Nguyen and Hang Thi Thu Dinh contributed equally to this work.

This article is part of the Topical Collection on Medicine

Electronic supplementary material The online version of this article (https://doi.org/10.1007/s42399-019-00074-5) contains supplementary material, which is available to authorized users.

Son Thai Nguyen

ntson65@yahoo.com

Hang Thi Thu Dinh

hangdinhbio@gmail.com

Minh Ngoc Nghiem

nghiemminh@igr.ac.vn

1 Department of Medical Microbiology, Military Hospital 103, Vietnam Military Medical University, Hanoi, Vietnam

2 Division of Microbiology, Institute of Biomedicine and Pharmacy, Vietnam Military Medical University, Hanoi, Vietnam

3 Institute of Genome Research, Vietnam Academy of Science and Technology, Hanoi, Vietnam

\section{Background}

Bacillus anthracis and Yersinia pestis are the pathogenic agents of anthrax and bubonic plague, respectively. They are zoonotic pathogens causing life-threatening diseases in humans and animals and posing high risks for public health $[1,2]$. The Centers for Disease Control and Prevention (CDC) classified these pathogens as bioterrorism agents in category A of the most dangerous group of biological agents [3]. One of the most typical examples of bioterrorism, the "Anthrax letters" case in September 2001 in New York, USA, has affected the population with a huge impact at a psychological and political level [4]. Rapid screening of suspected specimens, therefore, helps to control the spread of epidemics, to contain the causative agents and to ensure the accurate and specific treatment.

Currently, there are a number of diagnostic methods for identification of $B$. anthracis and $Y$. pestis based on their phenotypic features, including bacteriological isolation, serology, and immunoassays. These approaches are time- 
consuming and required the use of skillful personnel and biosafety level 3 (BSL3) laboratory [3]. Moreover, serology and immune assays have limited sensitivity and specificity, particularly in case of immune assay-based rapid tests [5]. In recent years, a number of molecular approaches targeting genomic DNA have been developed for rapid and accurate identification of $B$. anthracis and $Y$. pestis, including conventional and simple multiplex polymerase chain reaction (mPCR), real-time PCR, and microarray assay applied for detection/discrimination of the pathogens in humans and environment [6-12]. Generally, in these assays, the detection has been targeted to virulence gene(s) on a symbiotic plasmid of each pathogen only; thus, identification and discrimination between pathogenic strains and non-pathogenic strains lacking either one or both virulence plasmids were limited. For $B$. anthracis, accurate diagnosis of pathogenic strains in nature is based on simultaneous detection of specific genes on their chromosomes and two virulent plasmids, pXO1 and pXO2. One of these plasmids may be lost in some strains, leading to a decrease in their pathogenicity [13]. Similarly, Y. pestis contains two virulence plasmids, pPCP1 and pMT1, with their respective genes encoding for virulence factors $[14,15]$. In some cases, these plasmids are unstable and easy to be lost due to the environmental conditions or during serial subcultures $[14,16$, 17]. Other factors that may inhibit successful PCR or generate false products regarding amplification of $B$. anthracis and $Y$. pestis from the environmental samples are the substances usually found in soil and water. Therefore, internal amplification control (IAC) in diagnostic PCR assays is necessary to be designed to detect false negative amplifications [18].

These two contagious pathogens have been detected and persisted in some areas in Vietnam. The sporadic cases of anthrax still occasionally appear in the North of Vietnam [19], and Y. pestis still persists in rodents in the Tay Nguyen area has the potential to cause epidemics [20]. An accurate and rapid identification assay to detect these pathogens is essential for early treatment and prevention of epidemic breaks. In the present study, we describe a rapid hexaplex PCR assay simultaneously targeting six genes developed for accurate identification of pathogenic $B$. anthracis and $Y$. pestis with the IAC included in the reaction to verify the positive and to avoid false negative results.

\section{Materials and Methods}

Experiments were carried out in the Division of Microbiology, the Institute of Biomedicine and Pharmacy, and the Department of Medical Microbiology, Military Hospital 103, Vietnam Military Medical University (VMMU).

\section{Bacterial Strains and Growth Conditions}

The strains of Bacillus anthracis 17JB, Bacillus cereus ATCC 6464, Yersinia enterocolitica ATCC 9610 and Escherichia coli ATCC 25922, are used as reference strains in this study. The screening bacterial strains from suspected various soil and aquatic environments (B1, B3-5, B8-13, B17-22, Y1), patients (B2, B6, B23, Y2-11), and livestock animals (B7, B1416) in the north of Vietnam were collected by the research teams of Military Institute of Preventive Medicine, Vietnam Military Department of Medicine and VMMU, identified by conventional culture and PCR. Reference and screening bacterial strains were grown on broth of brain heart infusion (BHI) (Difco Laboratories, USA) and 5\% ( $v / v)$ sheep blood agar plates (BioMérieux, Marcy l'Etoile, France) at $37^{\circ} \mathrm{C}$ for $24 \mathrm{~h}$ for $B$. anthracis, and at $28^{\circ} \mathrm{C}$ for $48 \mathrm{~h}$ for Y. pestis. Other reference strains were routinely cultivated on $5 \%(v / v)$ sheep blood agar overnight at $37^{\circ} \mathrm{C}$. Presumptive colonies studied the shape, the structure, and the colony characteristics; besides, Gram staining and biochemical tests of the isolates were carried out according to the manufacturer's instructions (API50CHB, API20NE, BioMérieux, Marcy l'Etoile, France, Vitek2 Compact).

\section{Genomic DNA Extraction from Bacterial Culture}

All bacterial culture samples were heat inactivated at $121{ }^{\circ} \mathrm{C}$ for $20 \mathrm{~min}$, and follow-up experiments were carried out in a BSL2 facility [21]. Genomic DNA was extracted using the commercial QIAamp DNA Mini Kit (Qiagen $\mathrm{GmbH}$, Hilden, Germany) according to the manufacturer's instructions. Extracted DNA samples were prepared at a concentration of $10^{5}$ copies $/ \mu$ and stored at $4{ }^{\circ} \mathrm{C}$ until use.

\section{Primer Design and Standard PCR Assays}

Sequences of specific genes in GenBank for both pathogenic and non-pathogenic B. anthracis and Y. pestis were selected as references for primer design for multiplex PCR. The vrrA (chromosome), pagA (pXO1 virulent plasmid), and capA (pXO2 virulent plasmid) genes, in particular, were selected as markers for B. anthracis. For Y. pestis, the ypo2088 (chromosome), pla (pPCP1 virulent plasmid), and cafl (pMT1 virulent plasmid) genes, similarly, were selected. All primer pairs for the selected genes were self-designed in silico by using Primer3 tool in the National Center for Biotechnology Information (NCBI, https://www.ncbi.nlm.nih.gov/) and BioEdit software. List of primers designed, target genes, and amplicon sizes are shown in Table 1. Standard PCR and multiplex PCR assays were performed in a Master proS Cycler (Eppendorf, Hamburg, Germany) in the volume of $25 \mu$ containing $1 \times$ PCR buffer $(2 \mathrm{mM} \mathrm{MgCl} 2), 0.2 \mathrm{mM}$ of each dNTP, $0.2 \mu \mathrm{M}$ of each primer, $1 \mathrm{U}$ Dream Taq 
Table 1 List of primer pairs developed for internal amplification control and multiplex PCR in this study

\begin{tabular}{|c|c|c|c|c|}
\hline Organism & Primer & Gene target & Sequence $\left(5^{\prime}\right.$ to $\left.3^{\prime}\right)$ & $\begin{array}{l}\text { Amplicon } \\
\text { (bp) }\end{array}$ \\
\hline $\begin{array}{l}\text { Competitive IAC originated from } \\
\text { B. anthracis }\end{array}$ & $\begin{array}{l}\mathrm{IC} 1 \mathrm{~F} / B a m \mathrm{HI} \\
\mathrm{IC} 1 \mathrm{R} / N d e \mathrm{I}\end{array}$ & Lethal factor gene & $\begin{array}{l}\text { GTGGATCCTATCTTGCCAGC } \\
\text { ATCCGT } \\
\text { TCCATATGAAAGAGGCAGCA } \\
\text { GAAAAGC }\end{array}$ & 654 \\
\hline \multirow[t]{3}{*}{ B. anthracis } & $\begin{array}{l}\text { vrrAF1* } \\
\text { vrrAR1* }\end{array}$ & Variable repeat region $\mathrm{A}$ & $\begin{array}{l}\text { CTGTAAGCCCTGTCGTCGAA } \\
\text { CCTCGCGCACTTCTTTTTCT }\end{array}$ & 222 \\
\hline & $\begin{array}{l}\operatorname{pagAF} 1 * \\
\operatorname{pagAR} 1 *\end{array}$ & Protective antigen gene & $\begin{array}{l}\text { AAATGGAGCACGGCTTCTGA } \\
\text { AGCCTGTATCCACCCTCACT }\end{array}$ & 751 \\
\hline & $\begin{array}{l}\text { capAF1* } \\
\text { capAR1* }\end{array}$ & CapA gene, IAC plasmid & $\begin{array}{l}\text { TGACGATGACGATGGTTGGT } \\
\text { GCTTCCTGTCTAGGACTCGG }\end{array}$ & 610,1000 \\
\hline \multirow[t]{3}{*}{ Y. pestis } & $\begin{array}{l}\text { ypoF1* } \\
\text { ypoR } 1 *\end{array}$ & $\begin{array}{l}\text { Ypo2088 putative methyltransferase } \\
\text { gene }\end{array}$ & $\begin{array}{l}\text { GGATGAGATAACGCGGGTGT } \\
\text { AGAGAATCGTGATGCCGTCC }\end{array}$ & 103 \\
\hline & $\begin{array}{l}\text { plaF1* } \\
\text { plaR1* }\end{array}$ & Plasminogen activator gene & $\begin{array}{l}\text { CGGGATGCTGAGTGGAAAGT } \\
\text { ATTACCCGCACTCCTTTCGG }\end{array}$ & 438 \\
\hline & $\begin{array}{l}\text { cafF } 1 * \\
\text { cafR } 1 *\end{array}$ & F1 capsular antigen gene & $\begin{array}{l}\text { CGCTTACTCTTGGCGGCTAT } \\
\text { GCTGCAAGTTTACCGCCTTT }\end{array}$ & 271 \\
\hline
\end{tabular}

* Primers used in multiplex PCR

polymerase (Thermo Scientific, Wilmington, DE, USA), and $5 \mu \mathrm{l}$ genomic DNA (approximately $10 \mathrm{ng}$ ). Thermocycling parameters were as follows: an initial denaturation at $94{ }^{\circ} \mathrm{C}$ for $4 \mathrm{~min}$, followed by 30 cycles consisting of $94^{\circ} \mathrm{C}$ for $1 \mathrm{~min}$, $56{ }^{\circ} \mathrm{C}$ for $45 \mathrm{~s}$, and $72{ }^{\circ} \mathrm{C}$ for $50 \mathrm{~s}$, and a final extension at $72{ }^{\circ} \mathrm{C}$ for $7 \mathrm{~min}$.

\section{Optimization of Hexaplex PCR Assay}

A hexaplex PCR was carried out by simultaneous addition of six primer pairs for vrrA, pagA, capA, ypo2088, pla, and cafl genes (Table 1) in the same reaction mixture. Initially, equimolar primer concentration of $0.2 \mu \mathrm{M}$ each was used in the multiplex PCR and adjustment of the proportion of each primer pair from 0.1 to $0.6 \mu \mathrm{M}$ in the reactions to obtain optimal amplification of targeted genes. Secondly, a gradient of PCR annealing temperature was performed from 54 to $58{ }^{\circ} \mathrm{C}$ to find the optimal temperature allowing simultaneous and specific amplification of six different amplicons. Additionally, to increase the product yield of hexaplex PCR assay, other PCR components were also evaluated including $\mathrm{MgCl}_{2} \quad 0.2-2.0 \mathrm{mM}$, dNTPs $0.25-0.8 \mathrm{mM}$, buffer $1-1.5 \times$, and number of PCR cycles from 30 to 40 cycles. Adjuvants such as BSA (bovine serum albumin), betaine (trimethylglycine) and DMSO (dimethyl sulfoxide) to be considered additional if necessary. After each amplification assay, PCR fragments were analyzed on $1.5 \%$ agarose gel electrophoresis in $0.5 \times \mathrm{TBE}$ buffer at $110 \mathrm{~V}$ for $50 \mathrm{~min}$ and $0.5 \mu \mathrm{g} / \mathrm{ml}$ of ethidium bromide (Bio Basic, Markham, Ontario, Canada) stained and visualized with a BioDoc-it Imaging System (UVP, Upland, CA, USA).

\section{Sensitivity and Specificity of the Hexaplex PCR Assay}

Genomic DNA samples from B. anthracis and $Y$. pestis were serially diluted from approximately $20 \mathrm{ng} / \mu \mathrm{l}$ to $20 \mathrm{fg} / \mu \mathrm{l}$ with $5 \mu \mathrm{l}$ from each dilution used for hexaplex PCR to identify the analytical sensitivity, corresponding to a range from $2 \times 10^{7}$ to 20 genome copies/reaction, respectively. Specificity of primer pairs in the developed hexaplex PCR was assessed using genomic DNA samples from $B$. cereus, $Y$. enterocolitica, and E. coli. The time stability of developed PCR assay which was stored at $-20{ }^{\circ} \mathrm{C}$ was tested monthly in the same standard concentration sample of $B$. anthracis and $Y$. pestis.

\section{Hexaplex PCR Assay for the Detection of Soil Pseudo-Sample Contaminated Bacteria}

In order to validate the multiplex PCR with the environment sample, we spiked the inactivated $B$. anthracis and $Y$. pestis culture samples into the soil. The final concentration of pseudo-samples was from $10^{0}$ to $10^{7}$ colony forming units/ milliliter $(\mathrm{CFU} / \mathrm{ml})$. One milliliter of each sample was added to aliquots of soil $(1 \mathrm{~g})$ and incubated the contaminated soil for $24 \mathrm{~h}$ [22]. The suspension that was created from the soil by adding $2 \mathrm{ml}$ of distilled water and carefully vortex was used to extract the DNA using the Soil DNA isolation kit (Norgen Biotek Corp., Canada) according to the manufacturer's instruction.

\section{Internal Amplification Control Designing}

A competitive IAC used to verify the diagnosis results was a chimeric plasmid, and its construction is briefly described. A $654 \mathrm{bp}$ fragment of lef gene of B. anthracis was amplified 
using IC1F/BamHI and IC1R/NdeI primer pairs (Table 1). This PCR product was cloned into a pJET1.2-capA plasmid consisting of the sequence of pJET1.2-blunt vector (Thermo Fisher Scientific Inc., Waltham, USA) and the capA gene of B. anthracis after it was linearized by Bam $\mathrm{HI}$ and NdeI restriction enzyme. The ligation product was conventionally transformed into E. coli DH5 $\alpha$ (Invitrogen Corp., Carlsbad, USA) [18]. The recombinant IAC named pJET1.2-capA-IC1 was sequenced to confirm its identity. Determination of the lowest reproducible IAC concentration during genomic DNA extraction was evaluated from $10^{9}$ to $10^{\circ}$ copies/sample from IAC dilutions.

\section{Evaluation of Developed Hexaplex PCR with IAC}

Evaluation of hexaplex PCR assay with pJET1.2-capA-IC1 was performed with a total of 38 samples, including B. anthracis $(n=11), B$. cereus $(n=14), Y$. pestis $(n=1)$, $Y$. enterocolitica $(n=1)$, and E. coli $(n=11)$, and compared with conventional culture methods. Additionally, the strains of $B$. anthacis and $Y$. pestis specifically determined by the hexaplex PCR assay were exactly confirmed by gel extraction of target bands and direct Sanger sequencing.

All the experiments in the present study were performed in triplicate and controls included.

\section{Results}

\section{Selection and Primer Pair Design of Three Target Genes for B. anthracis and Three Target Genes for $Y$. pestis}

In $B$. anthracis, to distinguish between pathogenic strains and non-pathogenic strains, we selected both the pagA gene (751 bp amplicon) and capA gene (610 bp amplicon) from pXO1 and pXO2, respectively, and a $B$. anthracis-specific target of the variable repeat region $\mathrm{A}$ - the vrrA gene (222 bp amplicon) as a stable chromosomal marker for a $B$. anthracis detection triplex PCR assay.

Similarly, the pla and cafl are common target genes which are used to identify $Y$. pestis in molecular methods. Particularly, the pla gene (amplicon size $473 \mathrm{bp}$ ) encodes plasminogen activator located on the virulent plasmid pPCP1. Whereas, the cafF1/R1 primer pairs targeted the cafl gene (amplicon size $271 \mathrm{bp}$ ) located on the virulent pMT1 plasmid which encoded the F1 fraction. Furthermore, the ypo2088 gene (amplicon size $103 \mathrm{bp}$ ) is a specific chromosomal marker of $Y$. pestis. Uniplex PCR amplicons of different genes of $B$. anthracis as well as $Y$. pestis yielded the products of expected sizes on agarose gel electrophoresis. The specificity of the primer pairs was checked in pooled two DNA templates of $B$. anthracis and $Y$. pestis by tri-primer
PCR assays of each agent, to ensure that there was no crossamplification (Fig. 1, Table 1).

\section{Optimization of Hexaplex PCR Assay}

The optimization of a hexaplex PCR assay for high amplification efficiency of the specific PCR products has been conducted as follows. Firstly, the concentration of individual primer pairs was evaluated, and the optimized concentrations of three primer pairs for $B$. anthracis and three primer pairs for $Y$. pestis were 0.6 and $0.1 \mu \mathrm{M}$, respectively. Secondly, an optimal annealing temperature of $56{ }^{\circ} \mathrm{C}$ was found. Next, $\mathrm{MgCl}_{2}$ was obtained for $0.6 \mathrm{mM}$ as the best concentration. After the concentration of $\mathrm{MgCl}_{2}$ was determined as of $0.6 \mathrm{mM}$, the dNTP concentration from 0.25 to $0.8 \mathrm{mM}$ was tested and $0.25 \mu \mathrm{M}$ was found the most optimal concentration. Finally, other components found for the hexaplex PCR were 2.0 U of Dream Taq polymerase, $1.2 \times$ buffer, and 32 amplification cycles. The optimal mPCR assay revealed the presence of six amplicons clearly separated on agarose gel by the electrophoresis (Fig. 2).

\section{Evaluation of the Detection Capability for Multiplex PCR Assay}

The limit of detection of hexaplex PCR by using serious dilutions of bacterial genomic DNA as templates, for the individual detection of $B$. anthracis and $Y$. pestis, was $0.5 \mathrm{pg} /$ reaction, equivalent to approximately 100 bacterial cells. The sensitivity of hexaplex PCR with spiking soil study for $B$. anthracis and Y. pestis was about $10^{4} \mathrm{CFU} / \mathrm{ml}$, and there were no

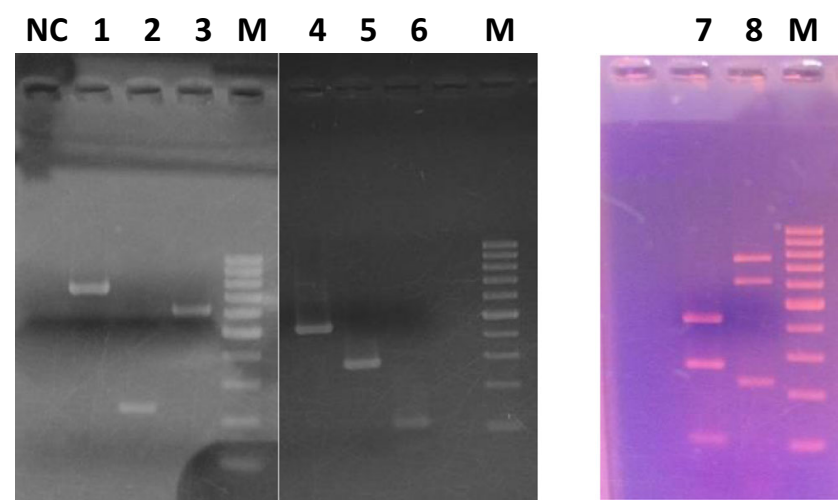

Fig. 1 Mono- and tri-primer PCR assay for the detection of B. anthracis and $Y$. pestis. Lane M, 100 bp DNA ladder (Thermo Scientific); NC, negative control (no DNA template). For the detection of $B$. anthracis: lane 1, mono-primer PCR assay consisting of pagAF1/R1 (virulent pXO1 plasmid); lane 2, capAF1/R1 (virulent $\mathrm{pXO} 2$ plasmid); lane 3, vrrAF1/R1 (chromosome). For the detection of $Y$. pestis: lane 4, mono-primer PCR assay consisting of plaAF1/R1 (virulent pPCP1 plasmid); lane 5, cafF1/ R1 (virulent pMT1 plasmid); lane 6, ypoF1/R1 (chromosome). For the detection of pathogenic $Y$. pestis and B. anthracis with pooled two DNA templates: lane 7 , tri-primer PCR assay including three primer pairs (ypoF1/R1, plaF1/R1, cafF1/R1); lane 8, tri-primer PCR assay including three primer pairs (vrrAF1/R1, pagAF1/R1, capAF1/R1) 


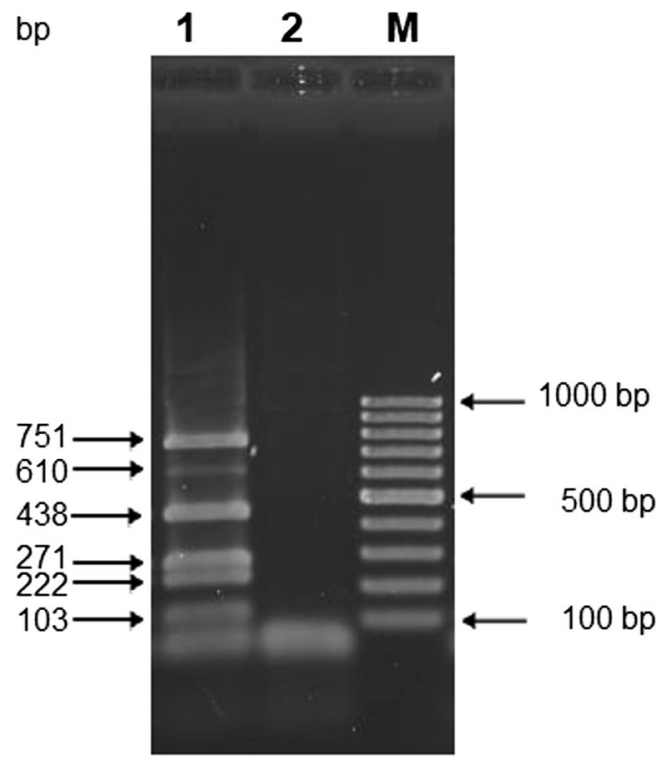

Fig. 2 Optimal hexaplex PCR assay with pooled two DNA templates of B. anthracis and $Y$. pestis. Lane M, 100 bp DNA ladder (Thermo Scientific); lane 1, hexaplex PCR assay; lane 2, negative control

notable differences in sensitivity for $B$. anthracis and for $Y$. pestis observed. However, some weak unspecific products appeared in the no-spiked and spiked soil samples (Fig. 3). The results proofed the overabundance of other microorganisms on soil samples in the study. Sequencing of six specific bands extracted from the gel confirmed the correspondent designed chromosomal and virulent targets of B. anthracis and $Y$. pestis (data not shown).

\section{Optimization and Evaluation of the Multiplex PCR Assay Including Internal Amplification Control}

Plasmid pJET1.2-capA-IC1 was designed to contain the primer sequence of capAF1/R1 of $B$. anthracis which was amplified simultaneously in the hexaplex PCR, for IAC product with a size of $1000 \mathrm{bp}$ different from the six diagnosis amplicons of the hexaplex PCR in terms of size. The IAC concentration of $5 \times 10^{4}$ copies per sample was determined, and the components of the hexaplex PCR assay including IAC were adjusted to $0.64 \mu \mathrm{M}$ concentration of capAF1/R1 primer set (Fig. 4). The IAC was added to the samples to control the DNA extraction procedure and verify PCR negative cases.

The developed hexaplex PCR assay was validated on 38 bacterial samples including the reference strains and screening isolates. Sensitivity and specificity were calculated for each target gene individually for the hexaplex PCR results of $B$. anthracis and $Y$. pestis. Out of 38 genomic DNA samples, 24 samples (B. anthracis 17JB, B1-B23) showed a PCR product of the $v r r A$ gene amplification (222 bp) for the "B. cereus" group, and four samples (B. anthracis 17JB, B2, B3, B23) showed two PCR products of both 751 and $610 \mathrm{bp}$ of the pagA gene and capA gene, respectively, which are specific

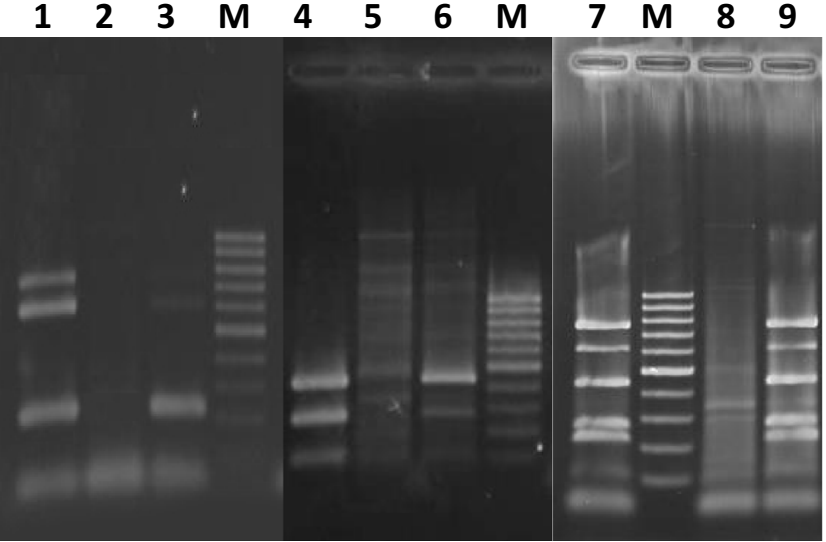

Fig. 3 Multiplex PCR products from soil samples inoculated with $B$. anthracis and $Y$. pestis. Lane M, 100 bp DNA ladder (Thermo Scientific); lanes 1, 4, and 7, bacterial culture of B. anthracis, Y. pestis, and B. anthracis and Y. pestis; lanes 2, 5, and 8, soil not inoculated with B. anthracis, Y. pestis, and B. anthracis and Y. pestis; lanes 3, 6, and 9, soil inoculated with $10^{6} \mathrm{CFU} / \mathrm{ml}$ of $B$. anthracis, $Y$. pestis, and B. anthracis and $Y$. pestis

to pathogenic $B$. anthracis. One sample (B5) showed a single product of $751 \mathrm{bp}$ of the pagA gene present in the plasmid pXO1 in B. anthracis strain only and no amplification for the capA gene due to the absence of plasmid $\mathrm{pXO} 2$, indicating this is of a not fully virulent strain. One sample showed three bands of 103, 275, and $438 \mathrm{bp}$, which are specific to pathogenic $Y$. pestis (Y1). The rest samples did not show any band except IAC product in all examined samples (illustrated in Fig. 4). The hexaplex PCR assay had, thus, $100 \%$ specificity for Y. pestis.

\section{Discussion}

Rapid, reliable, and simultaneous identification of CDC category A bioterrorism agent plays a crucial role in disease prevention. In this study, we have developed and evaluated a novel hexaplex PCR assay for simultaneous detection of pathogenic $B$. anthracis and $Y$. pestis as well as discrimination with non-pathogenic strains in a single PCR tube. A multiplex PCR assay comprising a total of six primer pairs including vrrAF1/ $\mathrm{R} 1$, pagAF1/R1, capAF1/R1, ypoF1/R1, plaF1/R1, and cafF1/R1 for B. anthracis and $Y$. pestis detection, respectively, was developed. Especially, the recombinant IAC, namely pJET1.2-capA-IC1, was designed with primer capAF1/R1 and was successfully co-amplified in the hexaplex PCR assay.

In $B$. anthracis, the pagA gene which encodes the protective antigen belonging to the virulent plasmid $\mathrm{pXO} 1$ is recommended by the World Health Organization (WHO) [19]. Besides, the second virulent plasmid of $B$. anthracis, $\mathrm{pXO} 2$, contains the capA, capB, and $\operatorname{cap} C$ genes encoding poly-Dglutamic capsule, in which the capA gene was widely used for diagnosis of $B$. anthracis [7, 23, 24]. In Y. pestis, both the pla 

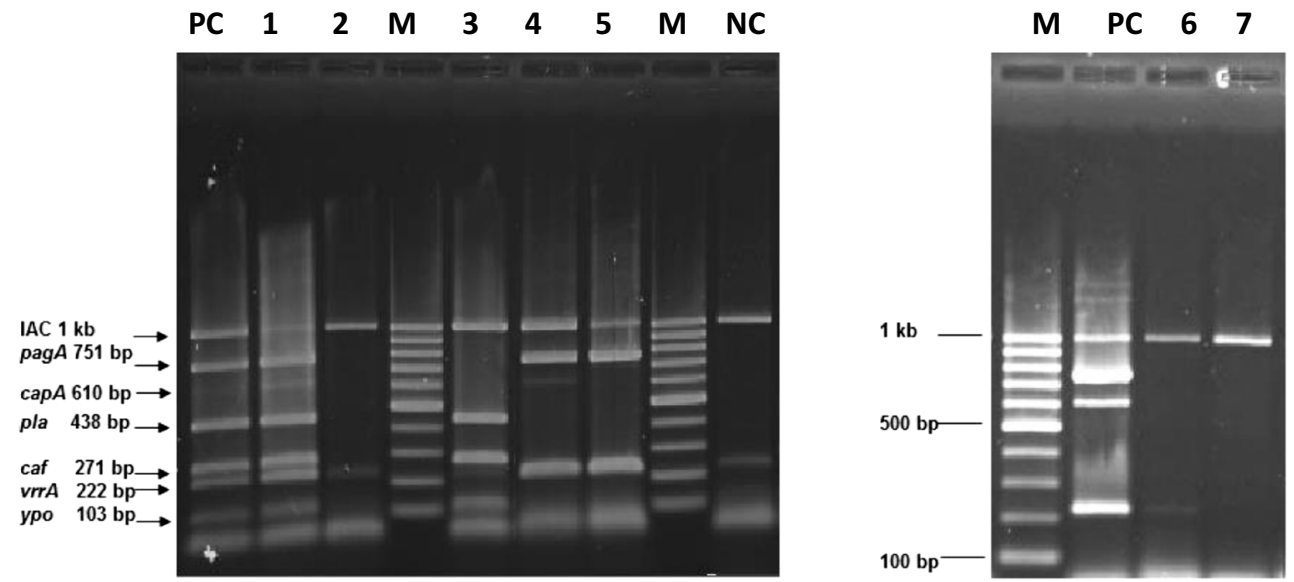

Fig. 4 Evaluation of the detectability of the optimal multiplex PCR including IAC from genomic DNA from screening isolates. M, $100 \mathrm{bp}$ DNA ladder (Thermo Scientific); $\mathrm{NC}$, negative control (B. cereus $+E$. coli); PC, positive control (B. anthracis and/or Y. pestis DNA); lane 1,

and cafl genes were commonly used as the targets because of high estimated copy numbers ( 3 and 4 in a cell), respectively, which improved the sensitivity of PCR $[12,25,26]$. Additionally, we have used the ypo2088 gene encoding for a putative methyltransferase to distinguish $Y$. pestis from other Enterobacteriaceae $[15,27]$.

In the developed hexaplex PCR assay, the recombinant IAC was also designed to control both DNA extraction and PCR processing, allowing the evaluation of the true negative to false negative results. In our study, we used no additional adjuvant supplementary materials, which were recommended by various authors to improve amplification efficiency and specificity of the multiplex PCR $[28,29]$. Our results revealed that the simultaneous hexaplex PCR assay with IAC was effectively optimized in this study.

However, the study has some limitations that will be the focus of our future work. Firstly, due to the lack of a clinical sample for both B. anthracis and Y. pestis, we could not evaluate the hexaplex PCR assay for diagnostics in clinical and environmental samples. Instead, we had to validate the mPCR assay in soil pseudo-samples contaminated with the cultured bacteria. Secondly, for the 6 non-pathogenic $B$. anthracis isolates (B1, B4, B6-8, B10), which do not harbor both the virulent plasmids, $\mathrm{pXO} 1$ and $\mathrm{pXO}$, which habored the vrrA gene as this gene is present in all species of " $B$. cereus" group including B. anthraics, B. cereus, and B. thuringensis [5], these isolates, therefore, were indistinguished from $B$. cereus used as reference strains. Thus, the use of both plasmids pXO1 and $\mathrm{pXO} 2$ in combination to accurately identify pathogenic $B$. anthracis was recommended [13, 30, 31]. Here, the three pathogenic $B$. anthracis were explored by the hexaplex PCR assay which was to the best of our knowledge the first report for cases of anthrax during two past decades in Vietnam. Altogether, the above multipex PCR assay has been proven the ability of accurate and simultaneous identification of
Y. pestis $\mathrm{Y} 1$ and $B$. anthracis $\mathrm{B} 2$; lane 2, B. anthracis $\mathrm{B} 4$; lane 3, Y. pestis Y1; lane 4, B. anthracis B3; lane 5, B. anthracis B5; lane 6, B. cereus B9; lane 7, Y. enterocolitica

pathogenic B. anthracis and Y. pestis as well as discrimination with non-pathogenic strains in nature.

\section{Conclusions}

The hexaplex PCR assay was developed for both pathogenic B. anthracis and $Y$. pestis to allow rapid and accurate detection of six target genes simultaneously including two genes on chromosomes and four genes on virulence plasmids of both bacteria, help distinguish strains that cause disease with nonpathogenic strains of $B$. anthracis as well as $Y$. pestis. Furthermore, we successfully developed the recombinant IAC for concurrent PCR amplification, making it as reliable proof for avoiding false negative results. The hexaplex PCR can, therefore, be a useful tool in screening for both pathogenic and non-pathogenic B. anthracis and $Y$. pestis, necessary in use for biodefense purposes and disease prevention.

Acknowledgments This work was supported by the Ministry of Defense (Vietnam) project. The authors would like to thank the Military Institute of Preventive Medicine, Vietnam Military Department of Medicine, for sampling. We also thank colleagues at the Military Hospital 103, Vietnam Military Medical University and Institute of Genome Research, Vietnam Academy of Science and Technology, for technical assistance.

\section{Compliance with Ethical Standards}

Ethics Approval and Consent to Participate Not applicable. The study was based on laboratory work performed with reference bacterial and screening strains isolated from environments, human, and herbivores. No data from human patients were used.

Consent for Publication Not applicable.

Conflict of Interest The authors declare that they have no conflict of interests. 
Open Access This article is distributed under the terms of the Creative Commons Attribution 4.0 International License (http:// creativecommons.org/licenses/by/4.0/), which permits unrestricted use, distribution, and reproduction in any medium, provided you give appropriate credit to the original author(s) and the source, provide a link to the Creative Commons license, and indicate if changes were made.

\section{References}

1. Schofield DA, Molineux IJ, Westwater C. Diagnostic bioluminescent phage for detection of Yersinia pestis. J Clin Microbiol. 2009;47(12):3887-94.

2. Koehler TM. Bacillus anthracis genetics and virulence gene regulation. Current topics in microbiology and immunology, vol. 271; 2002. p. 143-64.

3. Wagar E. Bioterrorism and the role of the clinical microbiology laboratory. Clin Microbiol Rev. 2016;29(1):175-89.

4. Jernigan DB, Raghunathan PL, Bell BP, Brechner R, Bresnitz EA, Butler JC, et al. Investigation of bioterrorism-related anthrax, United States, 2001: epidemiologic findings. Emerg Infect Dis. 2002;8(10):1019-28.

5. Irenge LM, Gala JL. Rapid detection methods for Bacillus anthracis in environmental samples: a review. Appl Microbiol Biotechnol. 2012;93(4):1411-22.

6. Brightwell G, Pearce M, Leslie D. Development of internal controls for PCR detection of Bacillus anthracis. Mol Cell Probes. 1998;12(6):367-77.

7. Skottman T, Piiparinen H, Hyytiainen H, Myllys V, Skurnik M, Nikkari S. Simultaneous real-time PCR detection of Bacillus anthracis, Francisella tularensis and Yersinia pestis. Eur J Clin Microbiol Infect Dis. 2007;26(3):207-11.

8. Tomioka K, Peredelchuk M, Zhu X, Arena R, Volokhov D, Selvapandiyan A, et al. A multiplex polymerase chain reaction microarray assay to detect bioterror pathogens in blood. J Mol Diagn. 2005;7(4):486-94.

9. Matero P, Hemmila H, Tomaso H, Piiparinen H, Rantakokko-Jalava $\mathrm{K}$, Nuotio L, et al. Rapid field detection assays for Bacillus anthracis, Brucella spp., Francisella tularensis and Yersinia pestis. Clin Microbiol Infect. 2011;17(1):34-43.

10. Molsa M, Hemmila H, Katz A, Niemimaa J, Forbes KM, Huitu O, et al. Monitoring biothreat agents (Francisella tularensis, Bacillus anthracis and Yersinia pestis) with a portable real-time PCR instrument. J Microbiol Methods. 2015;115:89-93.

11. Safari Foroshani N, Karami A, Pourali F. Simultaneous and rapid detection of Salmonella typhi, Bacillus anthracis, and Yersinia pestis by using multiplex polymerase chain reaction (PCR). Iran Red Crescent Med J. 2013;15(11):e9208.

12. Janse I, Hamidjaja RA, Bok JM, van Rotterdam BJ. Reliable detection of Bacillus anthracis, Francisella tularensis and Yersinia pestis by using multiplex qPCR including internal controls for nucleic acid extraction and amplification. BMC Microbiol. 2010;10:314.

13. Ogawa H, Fujikura D, Ohnuma M, Ohnishi N, Hang'ombe BM, Mimuro H, et al. A novel multiplex PCR discriminates Bacillus anthracis and its genetically related strains from other Bacillus cereus group species. PLoS One. 2015;10(3):e0122004.

14. Sodeinde OA, Subrahmanyam YV, Stark K, Quan T, Bao Y, Goguen JD. A surface protease and the invasive character of plague. Science. 1992;258(5084):1004-7.

15. Matero P, Pasanen T, Laukkanen R, Tissari P, Tarkka E, Vaara M, et al. Real-time multiplex PCR assay for detection of Yersinia pestis and Yersinia pseudotuberculosis. APMIS. 2009;117(1):34-44.
16. Turnbull PC, Hutson RA, Ward MJ, Jones MN, Quinn CP, Finnie $\mathrm{NJ}$, et al. Bacillus anthracis but not always anthrax. J Appl Bacteriol. 1992;72(1):21-8.

17. Marston CK, Hoffmaster AR, Wilson KE, Bragg SL, Plikaytis B, Brachman $\mathrm{P}$, et al. Effects of long-term storage on plasmid stability in Bacillus anthracis. Appl Environ Microbiol. 2005;71(12):7778-80.

18. Abdulmawjood A, Roth S, Bulte M. Two methods for construction of internal amplification controls for the detection of Escherichia coli $\mathrm{O} 157$ by polymerase chain reaction. Mol Cell Probes. 2002;16(5):335-9.

19. WHO. 2008. Anthrax in humans and animals-4th ed., p 20-60. I.World Health Organization. II .Food and Agriculture Organization of the United Nations. III .World Organisation for Animal Health.: WHO Press, World Health Organization, 20 Avenue Appia, 1211 Geneva 27, Switzerland.

20. Pham HV, Dang DT, Tran Minh NN, Nguyen ND, Nguyen TV. Correlates of environmental factors and human plague: an ecological study in Vietnam. Int J Epidemiol. 2009;38(6):1634-41.

21. Ellerbrok H, Nattermann H, Ozel M, Beutin L, Appel B, Pauli G. Rapid and sensitive identification of pathogenic and apathogenic Bacillus anthracis by real-time PCR. FEMS Microbiol Lett. 2002;214(1):51-9.

22. Gulledge JS, Luna VA, Luna AJ, Zartman R, Cannons AC. Detection of low numbers of Bacillus anthracis spores in three soils using five commercial DNA extraction methods with and without an enrichment step. J Appl Microbiol. 2010;109(5):1509-20.

23. Kurosaki Y, Sakuma T, Fukuma A, Fujinami Y, Kawamoto K, Kamo N, et al. A simple and sensitive method for detection of Bacillus anthracis by loop-mediated isothermal amplification. J Appl Microbiol. 2009;107(6):1947-56.

24. Venkateswaran K, Singh NK, Checinska Sielaff A, Pope RK, Bergman NH, van Tongeren SP, et al. Non-toxin-producing Bacillus cereus strains belonging to the $B$. anthracis clade isolated from the International Space Station. mSystems. 2017;2(3).

25. Feldman M, Harbeck M, Keller M, Spyrou MA, Rott A, Trautmann B, et al. A high-coverage Yersinia pestis genome from a sixthcentury Justinianic plague victim. Mol Biol Evol. 2016;33(11): 2911-23.

26. Parkhill J, Wren BW, Thomson NR, Titball RW, Holden MT, Prentice MB, et al. Genome sequence of Yersinia pestis, the causative agent of plague. Nature. 2001;413(6855):523-7.

27. Radnedge L, Agron PG, Worsham PL, Andersen GL. Genome plasticity in Yersinia pestis. Microbiology. 2002;148(Pt 6:1687-98.

28. Markoulatos P, Siafakas N, Moncany M. Multiplex polymerase chain reaction: a practical approach. J Clin Lab Anal. 2002;16(1): $47-51$.

29. Colmenero JD, Morata P, Ruiz-Mesa JD, Bautista D, Bermudez P, Bravo MJ, et al. Multiplex real-time polymerase chain reaction: a practical approach for rapid diagnosis of tuberculous and brucellar vertebral osteomyelitis. Spine (Phila Pa 1976). 2010;35(24): E1392-6.

30. Kim J, Gedi V, Lee SC, Cho JH, Moon JY, Yoon MY. Advances in anthrax detection: overview of bioprobes and biosensors. Appl Biochem Biotechnol. 2015;176(4):957-77.

31. Radnedge L, Agron PG, Hill KK, Jackson PJ, Ticknor LO, Keim P, et al. Genome differences that distinguish Bacillus anthracis from Bacillus cereus and Bacillus thuringiensis. Appl Environ Microbiol. 2003;69(5):2755-64.

Publisher's Note Springer Nature remains neutral with regard to jurisdictional claims in published maps and institutional affiliations. 